\title{
PURCHASING A GENERAL TICKET FOR PUBLIC TRANSPORT - A MEANS END APPROACH
}

\section{Highlights:}

- Heuristic versus systematic decision making when buying an annual season ticket for public transport.

- Find drivers for decision making when buying an annual season ticket for public transport.

- Means-end approach to gain insights into respondents' decision making processes. 


\title{
PURCHASING A GENERAL TICKET FOR PUBLIC TRANSPORT - A MEANS END APPROACH
}

\author{
Andreas Wittmer, Center for Aviation Competence, University of St. Gallen, \\ Dufourstrasse 40a, CH-9000 St. Gallen, Switzerland, email: \\ andreas.wittmer@unisg.ch,Phone: +4171224 2525 (corresponding author)
}

Barbara Riegler, Institute for Systemic Management and Public Governance, University of St. Gallen, Dufourstrasse 40a, CH-9000 St. Gallen, Switzerland, email: barbara.riegler@unisg.ch, Phone: +41712242525

\section{ABSTRACT}

Switzerland offers a dense network of public transport means. The Swiss General Ticket (GT) is a popular travel pass, which allows the use of most of the public transport facilities in Switzerland. The buying behavior for public transport general tickets underlies a complex decision process. Public transport customers can deal with the complexity in two ways: either one decides on choice heuristics according to ones rather emotional beliefs or decides systematically based on a rational price comparison. Judgment and decision theory creates the basis for the discussion of heuristic versus systematic decision-making in this paper.

The goal of the study is the explanation of the two consumer typologies when buying a GT along the continuum from more heuristically to systematically made decisions. Drivers for a more heuristically based as opposed to a systematically based decision process, taking into consideration endogenous and exogenous factors, are evaluated.

Literature provides some relevant heuristic and systematic decision factors. Primary research with railway customers in Switzerland (research panel) was conducted using an exploratory, semi-standardized approach using the laddering technique, which helps to identify relevant factors involved in the buying decision process. Functional attributes, which were put into context of higher-level personal values using the means-end approach, were detected. These functional attributes are the ones influencing a buying decision.

Results show that convenience factors have a high influence when it comes to purchasing a season ticket, but price is the crucial factor behind the final purchase decision.

Keywords: Transport, Railway, Consumer Behavior, Means-End Analysis 


\section{INTRODUCTION}

Switzerland is well known for its public transportation system and its dense network of railways. One of the Swiss population's favored travel passes is the Swiss General Ticket (GT), which is valid for one year and gives access to most of the public transport facilities. It provides an integrated public transport service free at the point of use at a price of CHF 5,800 for first class and CHF 3'550 for second class per adult in the year 2013. The costs are in the same range as those of using a mi-class car (Simma \& Axhausen, 2001). Simma and Axhausen (2001) revealed that although one would think that the ownership of a GT reduces car-usage due to the high costs of a GT, this is not the case. As the decision for a GT is not a substitutive one, it seems that price is not the only reason for GT ownership. Therefore, the question arises which factors drive the decision to purchase a GT.

Switzerland, as along with other European countries, is trying to control environmental problems by stimulating the use of public transportation. Due to the excessive use of private automobiles, urban regions are struggling with air pollution, high noise levels, as well as traffic congestion and parking problems (Apel, 1992; Bamberg et al., 2003). Thus, it is necessary to detect factors which positively affect public transportation choice and consequently the purchase of a GT. Some authors have already proposed travel demand management measures - including road pricing, traffic restrictions, introduction of new public transport, and the improvement of the service level of public transport (e.g. Pas, 1995; Kitamura et al., 1997; Fujii \& Kitamura, 2003). Everett and Watson (1987) stated that most of the travel demand management measures pursue the goal of increasing the service level of public transportation and/or decreasing the service level of private transportation. Service improvement of public transportation could be achieved by four factors: comfort, accessibility, supply and price (Eboli \& Mazzulla, 2008).

Due to the well-developed network of public transport in Switzerland, nearly all regions are easily accessible and public transport is offered with synchronized timetables. Season tickets, which are basically discounted and based on the average costs for using public transportation, contribute to augmenting the use of public transportation (FitzRoy \& Smith, 1999). According to Carbajo (1988) customers who make many trips tend to choose travel passes while customers with fewer trips purchase ordinary tickets. However, the selected option impacts the customers' travel patterns. Having purchased a travel pass, the number of trips might increase as it influences the marginal costs of travel. Doxey (1984) revealed that personal savings is the most important factor when deciding to purchase a travel pass. In addition to cost savings, travel passes offer the convenience of flexible travelling during its period of validity. White (1981) suggested that customers who have regularly purchased season tickets, and are thus used to its convenience, accept price increases and are willing to renew even if the costs are higher.

Although the above-mentioned studies propose that price is the major factor, other influential factors have barely been examined. In this paper we distinguish between instrumental factors (like price), and convenience factors which include factors other than price. In previous studies convenience factors have less often been considered when exploring influential factors on the purchase of season tickets in public transportation. That leads to the research question whether there are drivers, other than price, which influence the positive purchase decision of a GT. While price is a dominating factor when making systematic choices, we assume that convenience factors lead to a more heuristic purchase decision process. Thus, we subsequently intend to identify the factors that could be summarized as convenience factors. 
This paper addresses the issue of understanding customers' motivations to purchase a GT and to identify factors other than price, which drive the consumer to a positive purchase decision. From a managerial perspective the understanding of customers' motivations to purchase a GT assists in defining an appropriate marketing strategy.

We implemented an exploratory, semi-standardized approach by using the laddering technique, which helped to identify relevant factors involved in the buying decision process. We detected functional attributes, which were put into the context of higher level personal values using a means-end approach.

The study proceeds as follows: first we give a short overview of relevant buying behavior literature which leads to an outline of the research methodology based on the laddering technique and means-end theory. Consequently, we describe the results and finish with managerial implications.

\section{THEORETICAL BACKGROUND: CONSUMER DECISION- MAKING}

\section{Consumer Decision Making}

How people behave when facing the challenge of making decisions is a widely discussed question in common literature. The theory of judgment and decision making can be found in the disciplines psychology, sociology, business management, economics, political sciences, medical sciences, engineering, and other fields (Arkes \& Hammond, 1988). In the study at hand, the theory of judgment is used in the field of business management to explain the behavior of consumers; specifically, how consumers judge offerings and make buying decisions.

Judgment is "the mental or intellectual process of forming an opinion or evaluation by discerning and comparing," (Merriam-Webster, 2014) meaning the power or ability to decide on the basis of evidence (Arkes \& Hammond, 1988). The definition of decision is given by Merriam-Webster's Online Dictionary (2014) as "the act of settling or terminating... by giving judgment". A decision is an action taken with the intention to achieve favorable outcomes; hence, a decision is said to be successful if it leads to as satisfying outcomes as could have been reached with other actions (Yates, 1990). These definitions suggest that there is no big difference between judgment and decision-making in an ordinary discourse.

Although there are studies about judgment and decision making that go all the way back to 1918 (Thorndike, 1918; Edwards, 1954; Hammond, 1955), the systematic empirical study of judgment and decision making began in the 1960ies. This was especially the case in the field of cognitive psychology concentrating on motivational research. Decision analysis focuses on a priori decomposition, meaning separating the decision process into several components before the decision is made (Arkes \& Hammond, 1988). Therefore, consumers have to fulfill a multifaceted task when making buying decisions, as they are often faced with several alternatives and a large amount of product attributes which have to be evaluated (Solomon, 2013). Consumer decision-making models explain the problem solving process which starts with the recognition of a need. Consequently, in order to solve the problem, the customer has 
to pass through several steps: information search, alternative evaluation, purchase and postpurchase evaluation (Howard \& Sheth, 1969; Engel et al., 1973). The consumer has welldefined preferences and aims at maximizing utility. Thus, he or she chooses the option which maximizes his or her received value (Bettman et al., 1998).

Consumers are confronted with difficult value trade-offs, such as price versus convenience (Bettman et al., 1991). In this case, consumers either apply a heuristic or a systematic decision process (Gigerenzer \& Gaissmaier, 2011; Doyle, 1998). A systematic decision-making process focuses on the selection between alternatives which show the preferences individuals have when making a common decision. It is postulated that the individual disposes of all available information and applies rules of logic and statistics (Luce \& Raiffa, 1957; Raiffa, 1968; Kahneman et al., 1982; Doyle, 1998). A heuristic decision maker, on the other hand, ignores part of the available information and uses fewer resources to make a decision. Heuristic decision making strategies are less complex and, as only little information is needed, decisions are made faster. The heuristic perspective is based on divergences from systematic decision behavior, and is regarded as a cognitive approach which includes irrational and implicit factors and roles (Kahneman \& Frederick, 2002; Shah \& Oppenheimer, 2008). While systematic decision-making refers to rational reasoning, heuristic decisionmaking is linked to error-prone intuitions or irrationality (Gigerenzer \& Gaissmaier, 2011).

According to Simon rational choice models require "full information of all relevant alternatives as well as the consequences, probabilities, and a predictable world without surprises" (1979, p. 500). Bettman (1979) argued that the rational choice theory is insufficient for a deep understanding of how consumers behave when making a decision. The individual's brain is not able to process all the available information and thus applies specific decision rules to evaluate product alternatives. Reisen et al. (2008) found that in the early stages of the decision making process, individuals tend to use heuristic decision making strategies. In later stages, until the end of the process, alternatives are evaluated more carefully. During this phase consumers trade off price against other factors and finally make their purchase decision. Hence, it could be assumed that the instrumental factor price dominates systematic decisions, whereas other product attributes are prevailing factors when making heuristic choices.

\section{Travel Passes in Public Transportation}

Season tickets or travel passes allow the customers the use of an entire network of different means of public transport. Hence, season tickets are multi-modal in nature and cover the whole network of public transport (White, 1981). In Switzerland the GT is valid on all routes of the federal railway company SBB, most of the private railways, post busses, boats, and local public transport services - such as trams and busses - in most of the Swiss cities and agglomerations. In addition, GT owners receive discounts on many mountain railways.

Travel passes adopt a multimodal integrated fare system which is characterized by 1) a fixed fee that does not depend on travel length and frequency, 2) a given validity period, and 3) the possibility of interchanging means of transport (Marchese, 2006). From a passenger's point of view, the season ticket provides the advantage of not having to worry about purchasing individual tickets or having the required fare, as well as additional journeys not requiring extra fees. Moreover, boarding time is reduced and queuing at any ticket counter is not necessary (White, 1981). Thus, season tickets combine large consumption flexibility for the 
consumer due to their integrated tariff. Consumers are able to choose among several products at a moderate price (Marchese, 2006). To summarize, travel passes have the characteristics of a price advantage compared to regular tickets and several convenience factors, such as the validity on more than one means of public transport, and time savings due to possessing the ticket before starting the ride.

\section{RESEARCH PROCEDURE: LADDERING AND MEANS-END- ANALYSIS}

One way to analyze the structure how consumers select between alternatives in a choice situation is the means-end approach. Mainly developed by Gutman (1982), laddering techniques and the foundational means-end theory give insights into a customer's motivation behind purchasing a good. When applying laddering interview techniques, customers are forced to reflect on their motivations for buying a certain product or service. The qualitative analysis of the obtained results reveals consumption related cognitive structures (Grunert \& Grunert, 1995). The reason for selecting this method was to develop a deeper understanding of factors that influence the purchase decision for a GT. It gives an insight into the customers' feelings about a product. The most important benefit of the means-end analysis is that it provides a deeper understanding of customers' attitudes towards a product than other methods which focus merely on attributes or benefits (Gutman, 1982).

Commonly, the results of laddering interviews are displayed in a hierarchical network of meanings, which is called the hierarchical value map (HVM). HVMs illustrate concrete objects that are assigned to cognitive categories on different levels of abstraction, and are interlinked in chains and networks. In other words, a HVM shows relationships between product attributes (means), the consequences of consuming these products or services and the subsequent emerging personal values (ends) (Reynolds \& Gutman, 1988). As illustrated in figure 1, it links customers' knowledge about a product with their personal knowledge about functional as well as psychosocial consequences and values (Zanoli \& Naspetti, 2011). Attributes refer to the tangible and intangible characteristics of a product or service which are well known by the customer; consequences describe the importance of the attribute to the customer. According to Gutman (1982), consequences represent the psychological, physiological, or process results that a customer believes to achieve when using this product or service. Values describe a customer's universal life goals, which are the most personal and general consequences an individual reaches for (Rokeach, 1973).

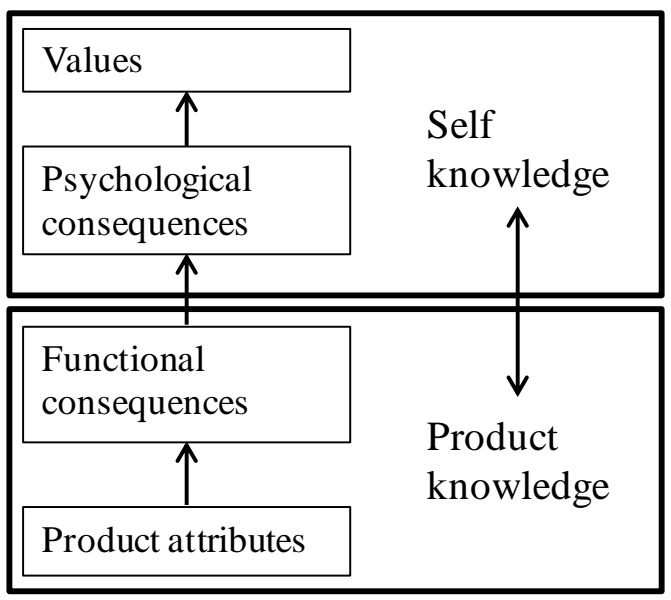


Figure 1: Means-end chain model (adapted from Zanoli \& Naspetti, 2011)

Usually, laddering is a tailored interview technique where researchers engage in in-depth and one-on-one interviews (soft laddering). The respondent is forced to produce ladders by answering in a way that each answer produces a new level of abstraction (Grunert et al., 1995). The process starts with questions about lower level attributes and ends with questions to reveal higher-level values (Phillips \& Reynolds, 2009). With the typical laddering interview question "Why is that important to you?", the researcher pursues the goal to determine sets of linkages between the elements. The interviewer questions why an attribute or consequence is important, so that each answer serves as a starting point for a further question. Thus, the researcher uncovers reasons why an attribute or consequence is important and marketers are able to understand how consumers process and perceive information about a product (Reynolds \& Gutman, 1988). However, in our study a so-called hard laddering approach is used. In comparison to soft laddering, hard laddering is a data collection technique which does not involve personal interviews, but instead either self-administered questionnaires or computerized data collection (Phillips \& Reynolds, 2009). Hard laddering is regarded as less time consuming, less expensive and reduces interviewer-bias (Botschen \& Hemetsberger, 1998). However, the challenge of hard laddering is that the respondents reach the highest level of abstraction on their own, without the control of a trained interviewer (Whitlark \& Allred, 2003). In this case, respondents might provide redundant answers that do not go beyond the consequence level. Herrmann et al. (1997) employed, in their study of the automotive industry, both hard and soft laddering and found that respondents provided very similar answers. Moreover, in the case of a large amount of respondents, hard laddering can be employed more efficiently (Russell et al., 2004).

The interpretation of laddering studies depends largely on the illustrated linkages between attributes, consequences and values in the HVM. Thus it is suggested that HVM are constructed by applying rigorous, justifiable and transparent methods (Leppard et. al., 2004). The analysis of laddering data starts with a content analysis where key elements are identified (Kassarjian, 1977). The key elements are summarized across all respondents, and coded and classified according to the attributes-consequences-values model. Subsequently, a matrix is constructed where the number of connections between the elements is indicated. The most dominant direct and indirect connections are then illustrated graphically in a tree-like map the HVM (Grunert et al., 1995).

\section{ANALYSIS AND FINDINGS}

This study is aimed at exploring and analyzing different levels of elements which drive the decision to purchase a GT for the Swiss public transportation system. We used a hard laddering technique for operationalization and analysis purposes in order to gain insights into the cognitive structure of the customers' purchase decision process.

Respondents were randomly chosen from a panel by a Swiss market research institute. They were asked to participate in the online survey concerning the purchase decision process for a GT and received the link to the online questionnaire. Respondents were first asked to write down at least two of the most important advantages of a GT as proposed by Henneberg et al. (2009). They were urged to answer as precisely as possible. For this purpose they were 
presented with three text boxes to indicate the perceived most important advantages. The subsequent laddering questions referred to these answers by asking "As the first advantage you mentioned.... Could you please describe why this advantage in relation to the use of public transport is of great importance to you?". This question was followed by the request to explain why the last statement was of particular relevance for them and, lastly, the respondents were asked which personal value they gained from the mentioned relevant factor. The laddering process, as presented to the respondents, is illustrated in figure 1.

1.
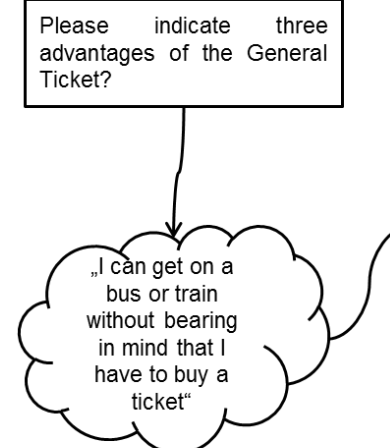

2.

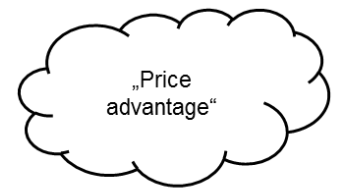

3.

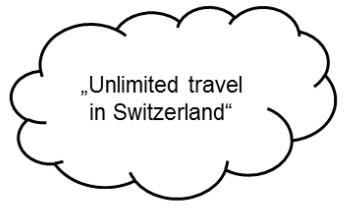

As the first advantage you mentioned ,I can get on a bus or train without bearing in mind that I have to buy a ticket". Could you please describe why

this advantage in relation to the use of public transport is of great importance to you?

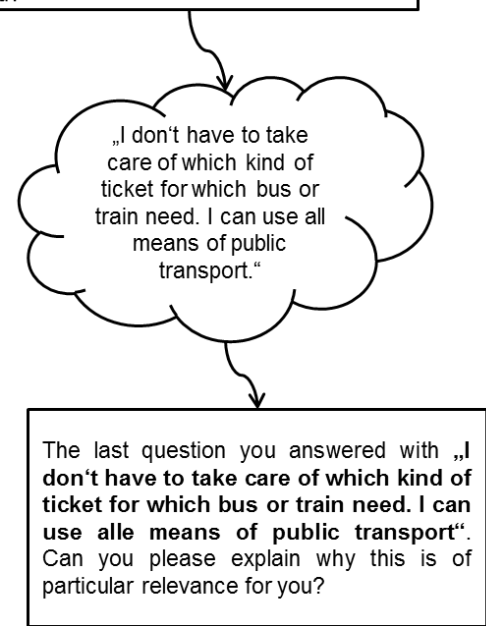

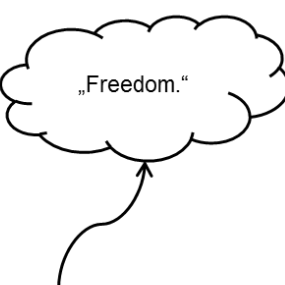

You wrote „I can go wherever I feel I want to go spontaneously". What is your personal value gained from this?

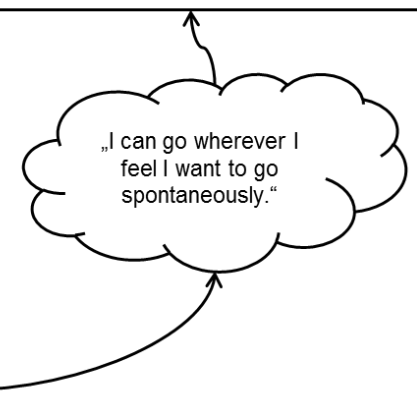

Figure 2: Laddering process in the questionnaire 
As proposed by Reynolds and Gutman (1988), the analysis of the data was completed in three steps. Firstly, sequences of attributes, consequences and values were coded with the support of the software program LadderUX. LadderUX assists in categorizing the answers from the questionnaire as either attributes, consequences or values (Vanden Abeele et al., 2012). As a first step, categories were developed in order to compare and group the answers. Categories were identified by defining key words. To enhance the reliability of the results, a second coder was assigned to that task (Grunert et al., 2001). In the second phase the number of links and associations between the elements on the different levels was counted and listed in the implication matrix. The implication matrix shows direct and indirect connections in the ladder. Direct connections relate to cases where the elements directly refer to one another. Indirect connections show intervening constructs, meaning that two elements are separated by at least one intervening element. The matrix then serves as a bridge between the qualitative and the quantitative aspects of the laddering technique as it shows the frequency of the connections (Deeter-Schmelz et al., 2002). Finally, the HVM was created consisting of nodes which represent the most important linkages between attributes, consequences and values.

\section{Sample Description}

The online study resulted in a convenience sample of 138 usable questionnaires. The sample includes slightly more female $(50.7 \%)$ than male $(49.3 \%)$ participants. On average the respondents are 50 years old, live in two person households, are employed $(63 \%)$ and earn between 9,000 and 12,000 Swiss francs per month (total household income) before taxes (28 \%). $55.8 \%$ of the respondents own a General Ticket (GT) for the Swiss public transportation system, $71.4 \%$ of them travel in first class and $28.6 \%$ in second class. Respondents who own a GT use public transportation on average 4.27 days per week for commuting purposes and travel 3.00 times per week for leisure purposes. Non-GT owners use public transportation for commuting on average 2.38 days and for leisure purposes 2.58 times per week.

\section{Laddering Results}

At the beginning of the laddering process, the respondents were requested to indicate the three most important advantages of owning a GT. They were asked to mention at least two benefits. In the analysis of the data we distinguished between GT owners and non-GT owners. Results show that $15.6 \%$ of the respondents who own a GT mentioned price as the first advantage. As illustrated in table 1, the remaining $84.4 \%$ indicated factors like no need to buy a ticket, unlimited travel, comfort and one ticket for all public ground transport offers as the most important benefits. Comfort is the most mentioned advantage, as GT owners appreciate that they can avoid traffic jams or searching for parking spaces when using public transport. While travelling, customers are able to relax and to concentrate on things other than traffic. The second most important advantage is the fact that customers are able to board means of public transport at every station without needing to buy a ticket. Another great advantage is that one single ticket allows travel throughout Switzerland using most of the different means of public transport. Unlimited travel refers to the opportunity of travelling any time to any place without any temporal or geographical constraints. 


\begin{tabular}{|l|r|r|r|}
\hline GT owners & $\begin{array}{l}\text { Advantage 1 } \\
(\mathrm{n}=77)\end{array}$ & $\begin{array}{l}\text { Advantage2 } \\
(\mathrm{n}=73)\end{array}$ & $\begin{array}{l}\text { Advantage 3 } \\
(\mathrm{n}=37)\end{array}$ \\
\hline Price & $15.6 \%$ & $17.8 \%$ & $29.7 \%$ \\
No need to buy a ticket & $24.7 \%$ & $15.1 \%$ & $10.8 \%$ \\
Comfort & $26.0 \%$ & $21.9 \%$ & $27.0 \%$ \\
One ticket for all & $19.5 \%$ & $24.7 \%$ & $8.2 \%$ \\
Unlimited travel & $14.2 \%$ & $20.5 \%$ & $21.6 \%$ \\
Environment & $0.0 \%$ & $0.0 \%$ & $2.7 \%$ \\
\hline Total & $\mathbf{1 0 0 . 0 \%}$ & $\mathbf{1 0 0 . 0 \%}$ & $\mathbf{1 0 0 . 0 \%}$ \\
\hline
\end{tabular}

Table 1: Advantages of owning a GT for GT owners

Similarly, table 2 shows that $81 \%$ of non-GT owners rated convenience factors as the most important advantage of owning a GT. The most important perceived benefit is that no ticket has to be bought prior to using public transport. Unlike GT owners, non-GT owners see an environmental advantage. When owning a GT, the decision whether to use a car or means of public transport is often made in favor to the latter.

\begin{tabular}{|l|r|r|r|}
\hline Non-GT owners & $\begin{array}{l}\text { Advantage 1 } \\
(\mathrm{n}=58)\end{array}$ & $\begin{array}{l}\text { Advantage2 } \\
(\mathrm{n}=57)\end{array}$ & $\begin{array}{l}\text { Advantage 3 } \\
(\mathrm{n}=9)\end{array}$ \\
\hline Price & $19.0 \%$ & $19.3 \%$ & $22.2 \%$ \\
No need to buy a ticket & $32.8 \%$ & $19.3 \%$ & $11.1 \%$ \\
Comfort & $5.2 \%$ & $12.3 \%$ & $0.0 \%$ \\
One ticket for all & $20.7 \%$ & $19.3 \%$ & $22.2 \%$ \\
Unlimited travel & $15.4 \%$ & $22.8 \%$ & $33.3 \%$ \\
Environment & $6.9 \%$ & $7.0 \%$ & $11.2 \%$ \\
\hline Total & $\mathbf{1 0 0 . 0 \%}$ & $\mathbf{1 0 0 . 0 \%}$ & $\mathbf{1 0 0 . 0 \%}$ \\
\hline
\end{tabular}

Table 2: Advantages of owning a GT for Non-GT owners

In the next step, the results of the laddering questions were analyzed. The HVM of GT (Figure 2) owners show the linkages between the coded elements. The coding process resulted in 40 elements being assigned to 8 attributes, 23 consequences and 9 values. An inspection of the implication matrix and various HVMs led to the determination of the cut-off level of four overall elements. The line between the elements was only included if the connection was mentioned at least four times. The strength of the line illustrates the number of respondents who mentioned a direct or indirect connection from one element to another. Hence, the thickness of the line represents the importance of the relationship. The lowest level of abstraction is presented by four attributes: price advantage, one ticket for all, unlimited travel and no need to buy a ticket. The HVM clearly shows that the most important connections are from price advantage (attribute) via cost savings to more money left for other things (consequences), and from no need to buy a ticket (attribute) via no queuing at ticket counter, time saving, practicability (consequences) to freedom, recreation and well-being (values). Another strong connection is shown between free mobility, flexibility (consequences) and freedom (value). Although the link from price advantage to cost savings shows the strongest line on the lower level, aspects linked to freedom and quality of life factors, like recreation and well-being, occupy a central position. Thus, it seems that for GT owners these values are 
the most important motivations behind purchasing a GT as they appear at all levels of the respondents' cognitive structures.

The HVM of non-GT (Figure 3) owners shows the linkages between the elements when the number of links exceeded the cut-off level of four. 34 elements were coded and assigned to 8 attributes, 20 consequences and 6 values. On the attribute level, the three elements no need to buy a ticket, unlimited travel and no need to own a car are displayed. The most important connection of this map starts with no need to buy a ticket (attribute) and goes via no queuing at ticket counter to time savings (consequences). The second most important connection ranges from no need to buy a ticket (attribute) via free mobility (consequence) to freedom (value) on the highest level. It can be seen that price advantage is, for non-GT owners, not as important as it is for GT owners. 


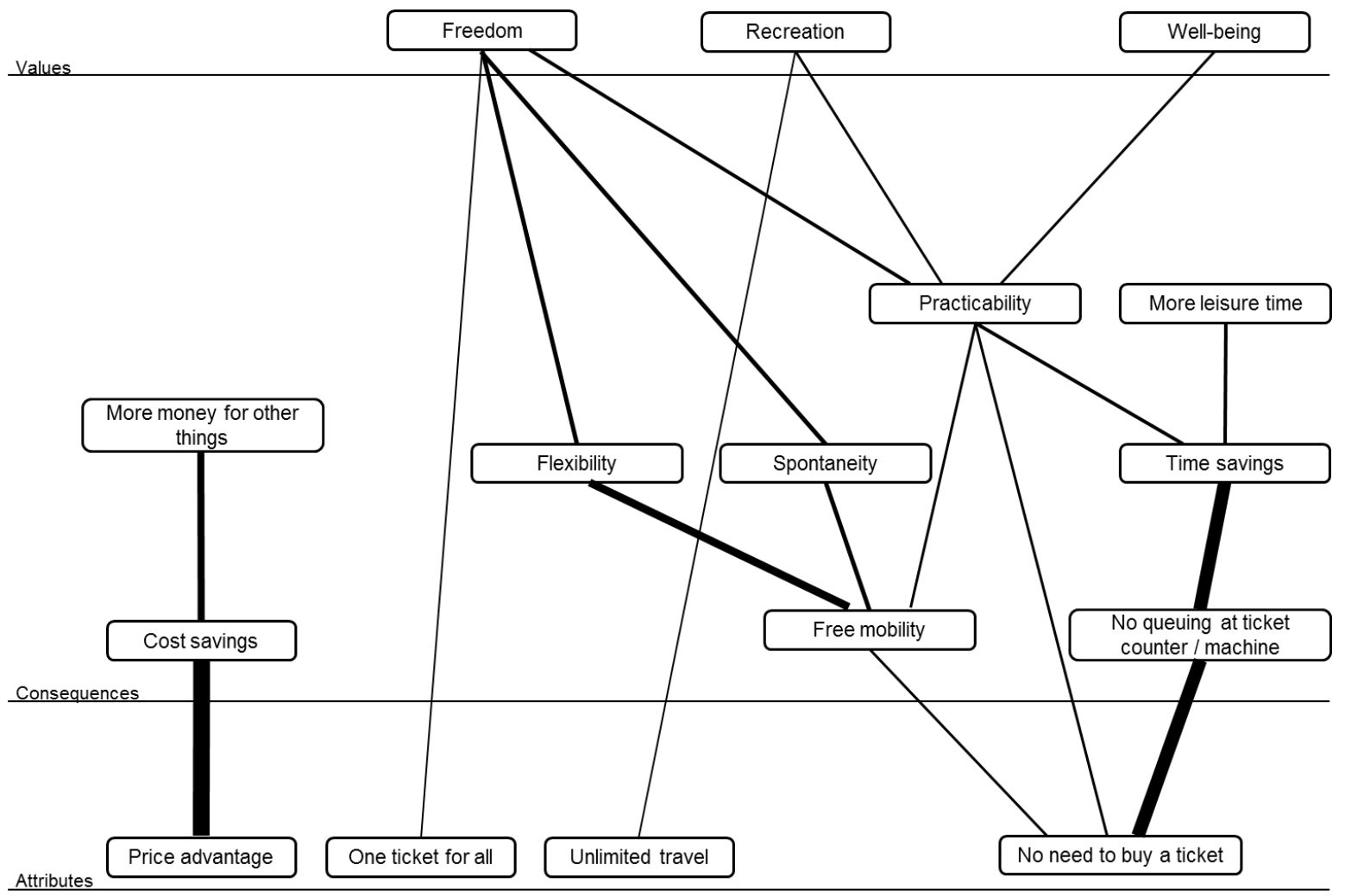

Figure 2: Hierarchical Value Map for GT owners (cut-off level = 4)

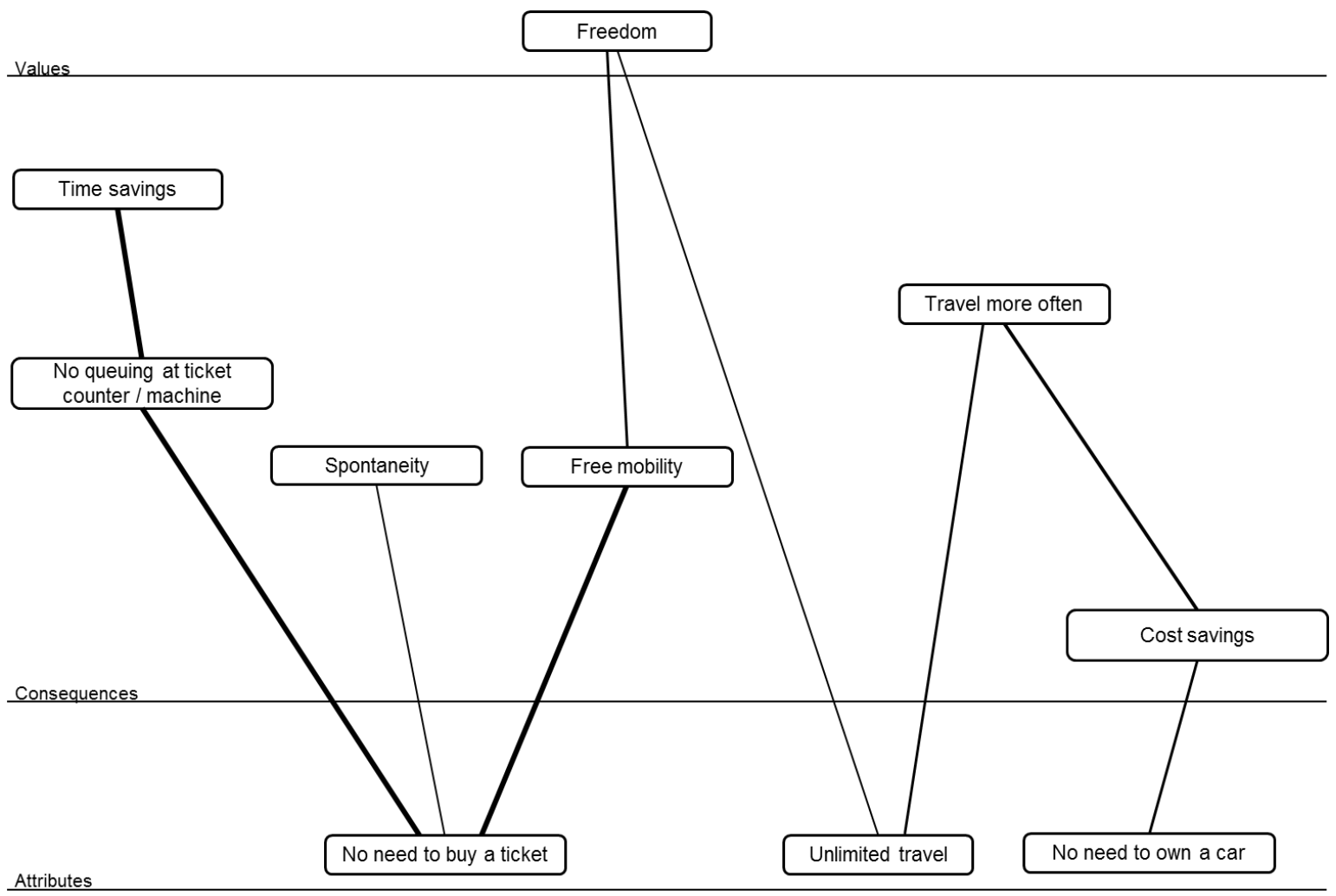

Figure 3: Hierarchical Value Map for Non-GT owners (cut-off level = 4) 
Subsequently, the respondents that own a GT were asked if there was any reason why they would no longer purchase a GT, while non-GT owners were asked why they did not own a GT. Content analysis showed that most of the respondents would refrain from purchasing a GT if there were a considerable price increase. The second most mentioned reason was a decline of passenger comfort caused by overcrowded trains or outdated train configurations. Other reasons were when growing older, they would no longer be able to travel that much; itinerary accuracy or unfavorable connections; change of work or moving to another place; restrictions in area validity, and decrease of costs for private transportation. Non-GT owners answered the question why they did not have a GT with the price for a GT was too high, they had a car or public transportation was not easily accessible for them.

\section{CONCLUSION}

The aim of this paper was to the detect drivers behind purchasing a GT for public transportation in Switzerland. While price evaluation in the purchase decision process is a typical systematic consideration (Bettman et al., 1998), this study should shed light on factors which dominate a heuristic decision making process.

A hard laddering technique has been applied in order to identify drivers other than price which influence the customers' purchase decision of a GT. Results show that the price advantage is still an important factor, but owning a GT has other dominating advantages. These advantages could be subsumed as convenience factors. The most essential of the convenience factors is the comfort which customers have when using public transportation instead of private transportation. Customers enjoy escaping traffic problems on the roads and use their time on public transport for other purposes instead. Even so, this factor is rather oriented to the question whether to use public transportation or privately owned cars. More important are the facts that no ticket has to be bought prior to travelling, as season tickets are valid on most of the Swiss means of public transportation. Customers do not need to queue up at ticket counters or machines and thus save time, which positively affects leisure time. The unlimited validity of a GT reinforces the customers' perception of free mobility and contributes to the feeling of flexibility and freedom. Looking at non-GT owners, price advantage is a critical factor, but not as important as either the fact that no ticket has to be bought or the GT's unlimited validity.

Although price advantage plays a minor role for positive buying decisions, it is a major factor when deciding not to purchase a GT. As White (1981) proposed, customers who are used to the convenience of owning a travel pass are willing to renew and accept price increases. This is not necessarily true for the Swiss customers. In the case of considerable price increases, customers would refrain from renewing their GT. Thus, we conclude that overall, GT owners are rather systematic buying decision makers with a price focus. They decide often by comparing prices of individual ticket prices over the year versus the price of a GT. This might also be the reason why non-GT owners do not possess a GT. They systematically trade off a GT's price against the frequency of using public transportation. 
To summarize, although convenience factors influence the purchase decision to a great extent, price is a major factor with an implicit impact. When the price increases considerably, also customers who regularly own a GT would refrain from renewing it. Hence, referring to Reisen et al. (2008), GT customers might decide rather heuristically in an early stage of the decision making process when convenience factors are preponderantly evaluated but weigh off these factors against price in the later stages.

\section{LIMITATIONS AND FUTURE RESEARCH}

This study was the first step of a major investigation into the purchase decision making process of GTs in Switzerland. The sample data of this study were not fully representative and biased for several reasons. The average age and the household income were rather on the high side. Furthermore, the larger number of GT owner participants purchased a first class GT, which did not represent reality. Even though there were some issues with the sample, it was possible to find value factors and learn about the different convenience factors. Hence, the next step of this research would be a quantitative survey with a representative sample of GT owners to test whether the results could be generalized. We suggest conducting conjoint analysis to examine which of the factors has the highest impact on a positive purchase decision of a GT. 


\section{REFERENCES}

Apel, D. (1992). Verkehrskonzepte für europäische Städte: Erfahrungen mit Strategien zur Beeinflussung der Verkehrsmittelwahl. Berlin, Germany: Deutsches Institut für Urbanistik, Beiträge zur Stadtforschung.

Arkes, H. R. \& Hammond, K. R. (1988). Judgment and decision making: An interdisciplinary reader. Cambridge, Cambridge University Press.

Bamberg, S., Ajzen, I. \& Schmidt, P. (2003). Choice of Travel Mode in the Theory of Planned Behavior: The Roles of Past Behavior, Habit, and Reasoned Action. Basic \& Applied Social Psychology

Bettman, J. R. (1979). An Information Processing Theory of Consumer Choice. Reading, MA: Addison-Wesley.

Bettman, J. R., Johnson, E. J., \& Payne, J. W. (1991). Consumer Decision Making. Englewood Cliffs, NJ: Prentice Hall.

Bettman, J. R., Luce, M. F., \& Payne, J. W. (1998). Constructive Consumer Choice Processes. Journal of Consumer Research, 25(3), 187-217.

Botschen, G., \& Hemetsberger, A. (1998). Diagnosing means-end structures to determine the degree of potential marketing program standardization. Journal of Business Research, 42(2), 151-159.

Carbajo, J. C. (1988). The Economics of Travel Passes: Non-Uniform Pricing in Transport. Journal of Transport Economics and Policy, 22 (2), 153-173

Deeter-Schmelz, D. R., Kennedy, K. N., \& Goebel, D. J. (2002). Understanding sales manager effectiveness: Linking attributes to sales force values. Industrial Marketing Management, 31(7), 617-626.

Doyle, J. (1998). Rational Decision Making, MIT draft article.

Doxey, L. B. (1984). Demand for Unlimited Use Transit Passes. Journal of Transport Economics and Policy, 18 (1), 7-22

Eboli, L. \& Mazzulla, G. (2008). A Stated Preference Experiment for Measuring Service Quality in Public Transport. Transportation Planning and Technology, 31 (5), 509-523

Edwards, W. (1954). The theory of decision making. Psychological Bulletin, 51, 380-417.

Engel, J. F., Kollat, D. T. \& Blackwell, R. D. (1973). Consumer behavior. New York, Holt, Rinehart and Winston.

Everett, P. B. \& Watson, B. G. (1987) Psychological contributions to transportation. In:

Stokols, D. \& Altman, I. (eds) Handbook of Environmental Psychology (Vol. 2, pp. 9871008). New York: Wiley

FitzRoy, F. \& Smith, I. (1999). Season tickets and the demand for public transport. Kyklos (52), 219-238

Fujii, S. \& Kitamura, R. (2003). What does a one-month free bus ticket do to habitual drivers? Transportation 30, 81-95 
Gigerenzer, G., \& Gaissmaier, W., (2011). Heuristic Decision Making. Annu. Rev. Psychol, 2011: 62, p. 451-482.

Grunert, K. G., Beckmann, S. C., \& Sorensen, E. (2001). Means-End Chains and Laddering: An Inventory of Problems and an Agenda for Research. Understanding consumer decision making: the means-end approach to marketing and advertising strategy, 63 .

Grunert, K. G., \& Grunert, S. C. (1995). Measuring subjective meaning structures by the laddering method: Theoretical considerations and methodological problems. International Journal of Research in Marketing, 12(3), 209-225.

Grunert, K. G., Grunert, S. C., \& Sørensen, E. (1995). Means-end chains and laddering: An inventory of problems and an agenda for research.

Gutman, J. (1982). A Means-End Chain Model Based on Consumer Categorization Processes. The Journal of Marketing, 46(2), 60-72.

Hammond, E.C. (1955). Probabilistic functioning and the clinical method. Psychological Review, 62(4), 255-262.

Henneberg, S. C., Gruber, T., Reppel, A., Ashnai, B., \& Naudé, P. (2009). Complaint management expectations: An online laddering analysis of small versus large firms. Industrial Marketing Management, 38(6), 584-598.

Herrmann, A., Huber, F., \& Gustaffson, A. (1997). From value-oriented quality improvement to customer satisfaction. In D. Johnson, A. Herrmann, F. Huber \& A. Gustafsson (Eds.), Customer retention in the automotive industry (pp. 93-115). Wiesbaden: Gabler.

Howard, J. A. \& Sheth, J. N. (1969). The theory of buyer behavior. New York, Wiley.

Kahneman, D., Shane, F. (2001). Representativeness revisited: Attribute substitution in intuitive judgment, In: Heuristics of Intuitive Judgment: Extensions and Applications, Eds. T. Gilovich, D. Griffin and D. Kahneman, New York: Cambridge University Press

Kassarjian, H. H. (1977). Content Analysis in Consumer Research. Journal of Consumer Research, 4(1), 8-18.

Kitamura R, Fujii S \& Pas EI (1997) Time use data for travel demand analysis: Toward the next generation of transportation planning methodologies. Transport Policy 4: 225-235.

Leppard, P., Russell, C. G., \& Cox, D. N. (2004). Improving means-end-chain studies by using a ranking method to construct hierarchical value maps. Food Quality and Preference, 15(5), 489-497.

Marchese, C. (2006). The economic rationale for integrated tariffs in local public transport. Annals of Regional Science, 875-886

Merriam-Webster (2014). Merriam-Webster Online: Dictionary and Thesaurus. Downloaded from http://www.merriam-webster.com/ on March 23rd, 2014.

Pas, E. (1995) The urban transportation planning process. In: Hanson S (ed) The Geography of Urban Transportation (pp. 53-77). Amsterdam: Elsevier. Ronis DL, Yates JF \& Kirscht JP (1989) Attitudes, decisions

Phillips, J. M., \& Reynolds, T. J. (2009). A hard look at hard laddering: A comparison of studies examining the hierarchical structure of means-end theory. Qualitative Market Research: An International Journal, 12(1), 83-99. 
Raffaele Zanoli, Simona Naspetti, (2002) "Consumer motivations in the purchase of organic food: A means-end approach", British Food Journal, Vol. 104 Iss: 8, pp.643 - 653

Reynolds, T. J., \& Gutman, J. (1988). Laddering Theroy, Method, Analysis, and Interpretation. Journal of Advertising Research, 28(1), 11-31.

Reisen, N., Hoffrage, U. \& Mast F. W. (2008). Identifying decision strategies in a consumer choice situation. Judgment and Decision Making 3, 641-58

Rokeach, M. J. (1973). The nature of human values. New York, NY: Free Press.

Russell, C. G., Flight, I., Leppard, P., van Lawick van Pabst, J. A., Syrette, J. A., \& Cox, D. N. (2004). A comparison of paper-and-pencil and computerised methods of "hard" laddering. Food Quality and Preference, 15(3), 279-291.

Shah, A.K.; Oppenheimer, D.M. (2008). Heuristics made easy: An effort-reduction framework, Psychological Bulletin, Vol 134(2), Mar 2008, 207-222.

Simon, H. A. (1979). Rational decision making in business organizations. American Economy Review 69, 493-513

Simma, A., \& Axhausen, K. W. (2001). Structures of commitment in mode use: a comparison of Switzerland, Germany and Great Britain. Transport Policy, 8(4), 279-288.

Solomon, M. R. (2013). Consumer Behavior: Buying, Having, and Being (10th ed.). Edinburgh: Pearson Education Ltd.

Thorndike, E.L. (1918). Fundamental theorems in judging men. Journal of Applied Psychology, 2, 67-76.

Vanden Abeele, V., Hauters, E., \& Zaman, B. (2012). Increasing the reliability and validity of quantitative laddering data with LadderUX. Paper presented at the Proceedings of the 2012 ACM annual conference extended abstracts on Human Factors in Computing Systems Extended Abstracts.

White, P. R. (1981). "Travelcard" tickets in urban public transport. Journal of Transport Economics and Policy, 15 (1), 17-34.

Whitlark, D. B., \& Allred, C. (2003). Driving your market: values research helps create a market-driving strategy. Marketing Research, Winter, 33-38.

Yates, J.F. (1990). Judgment and decision making. Englewood Cliffs, New Jersey: PrenticeHall. 
